\title{
Identification of key peptidoglycan hydrolases for morphogenesis, autolysis, and peptidoglycan composition of Lactobacillus plantarum WCFS1
}

\author{
Thomas Rolain ${ }^{1}$, Elvis Bernard ${ }^{1,2,3}$, Pascal Courtin ${ }^{2,3}$, Peter A Bron ${ }^{4,5,6}$, Michiel Kleerebezem, ${ }^{4,5}$,
} Marie-Pierre Chapot-Chartier ${ }^{2,3}$ and Pascal Hols ${ }^{1 *}$

\begin{abstract}
Background: Lactobacillus plantarum is commonly used in industrial fermentation processes. Selected strains are also marketed as probiotics for their health beneficial effects. Although the functional role of peptidoglycan-degrading enzymes is increasingly documented to be important for a range of bacterial processes and host-microbe interactions, little is known about their functional roles in lactobacilli. This knowledge holds important potential for developing more robust strains resistant to autolysis under stress conditions as well as peptidoglycan engineering for a better understanding of the contribution of released muramyl-peptides as probiotic immunomodulators.
\end{abstract}

Results: Here, we explored the functional role of the predicted peptidoglycan hydrolase (PGH) complement encoded in the genome of L. plantarum by systematic gene deletion. From twelve predicted PGH-encoding genes, nine could be individually inactivated and their corresponding mutant strains were characterized regarding their cell morphology, growth, and autolysis under various conditions. From this analysis, we identified two PGHs, the predicted $\mathrm{N}$-acetylglucosaminidase Acm2 and NplC/P60 D,L-endopeptidase LytA, as key determinants in the morphology of L. plantarum. Acm2 was demonstrated to be required for the ultimate step of cell separation of daughter cells, whereas LytA appeared to be required for cell shape maintenance and cell-wall integrity. We also showed by autolysis experiments that both PGHs are involved in the global autolytic process with a dominant role for Acm2 in all tested conditions, identifying Acm2 as the major autolysin of L. plantarum WCFS1. In addition, Acm2 and the putative $\mathrm{N}$-acetylmuramidase Lys2 were shown to play redundant roles in both cell separation and autolysis under stress conditions. Finally, the analysis of the peptidoglycan composition of Acm2- and LytA-deficient derivatives revealed their potential hydrolytic activities by the disappearance of specific cleavage products.

Conclusion: In this study, we showed that two PGHs of L. plantarum have a predominant physiological role in a range of growth conditions. We demonstrate that the $\mathrm{N}$-acetylglucosaminidase Acm 2 is the major autolysin whereas the $D, L-e n d o p e p t i d a s e ~ L y t A$ is a key morphogenic determinant. In addition, both PGHs have a direct impact on PG structure by generating a higher diversity of cleavage products that could be of importance for interaction with the innate immune system.

Keywords: Lactobacillus plantarum, Peptidoglycan, Autolysin, Peptidoglycan hydrolase, Glucosaminidase, Muropeptidase

\footnotetext{
* Correspondence: pascal.hols@uclouvain.be

'Biochimie et Génétique Moléculaire Bactérienne, Institut des Sciences de la

Vie, Université catholique de Louvain, Place Croix du Sud 5/L7.07.06,

Louvain-la-Neuve B-1348, Belgium

Full list of author information is available at the end of the article
} 


\section{Background}

The cell wall is an essential structure for the survival of bacteria, as it determines cell shape, and also preserves cell integrity from internal osmotic pressure [1]. In Gram-positive bacteria, peptidoglycan (PG) is a major compound of the cell wall. This polymer consists of the repeating disaccharide $N$-acetylmuramic acid- $(\beta-1,4)-N$-acetylglucosamine (MurNAc-GlcNAc) connected to a peptidic stem which is linked to MurNAc. The composition of the peptidic stem varies between bacteria and, in Lactobacillus plantarum, is composed of L-Ala, D-Glu, meso-diaminopimelic acid (mDAP), D-Ala and D-lactate as last moiety [2,3]. Neighboring glycan strands are cross-linked between the fourth amino-acid of the donor stem and the third amino-acid of the acceptor peptide, forming a three-dimensional network around the cell, termed sacculus [1]. Bacteria produce a variety of enzymes that are able to degrade PG. These enzymes are collectively called peptidoglycan hydrolases (PGH) or autolysins in the case they cleave PG glycan strands or cross-links of the producer strain resulting in the destruction of the PG mesh and cell lysis [1]. These enzymes have been shown to play a major role in different processes such as daughter cell separation, cell-wall turnover, autolysis, sporulation and germination, biofilm formation, resuscitation of dormant cells, and allolysis in genetic transformation [4,5]. Most of the PGHs display a modular organization composed of different domains usually associated with functions related to cell wall binding (e.g. LysM, SH3 domains) or PGH enzyme activity [6]. PGHs are divided into several major families depending on the activity of their catalytic domain; $N$-acetyl-glucosaminidases, -muramidases, and lytic transglycosylases hydrolyze $\beta-1$, 4-bonds of PG glycan strands, whereas $N$-acetyl-muramoylL-alanine amidases cleave the amide bond between the lactic acid side chain of MurNAc and L-Ala of the stem peptide and carboxy- and endo-peptidases cleave the peptidic stem [5]. In the last family, the D,D- and L,D-carboxypeptidases form a distinct group of PGHs since they do not destroy the PG mesh and are generally considered as PG maturation enzymes [1].

Lactobacilli, including Lactobacillus plantarum, are among the most predominant bacterial species of Firmicutes that are present in the mammalian intestinal tract [7]. Due to their ability to confer a health benefit on their host, specific strains of L. plantarum are marketed as probiotics $[8,9]$. It is also known that species of the genus Lactobacillus are able to interact with receptors of the immune system in the gastrointestinal tract through PGH-dependent processes such as autolysis and/or cell wall turnover that release muramyl-peptides or $\mathrm{PGH}$ fragments themselves [10-15]. In L. plantarum WCFS1, the analysis of its genome sequence has revealed the presence of 16 putative PGHs (carboxypeptidases are excluded), including 12 candidates displaying similarity with well-characterized PGHs, 3 hypothetical (lytic) transglycosylases containing a WY domain, and a pseudogene (acm3, three fragments) [12,16-18]. Among the well-characterized PGH homologs, Acm2, a putative $\mathrm{N}$-acetylglucosaminidase composed of a catalytic domain associated to five C-terminal $\mathrm{SH} 3$ domains and an $\mathrm{N}$ terminal $\mathrm{O}$-glycosylated region rich in Ala, Ser, and Thr (AST domain), was previously shown to be responsible for the separation of daughter cells $[19,20]$. In addition, we previously demonstrated that the PGH activity of Acm 2 and LytH (putative $N$-acetylmuramoyl-L-alanine amidase) could be modulated through $O$-acetylation of glycan chains of L. plantarum PG. MurNAc O-acetylation triggers LytH activity, whereas GlcNAc $O$-acetylation inhibits Acm2 activity [2].

Besides some recent studies performed in L. rhamnosus GG and L. casei BL23 that focused essentially on the characterization of specific major PGHs, information concerning the functional role of the complete arsenal of PGHs in lactobacilli is lacking [11,21,22]. In this study, we investigate the functional role of the 12 more probable candidates of the PGH complement of L. plantarum WCFS1 by a systematic gene deletion strategy. Characterization of mutant cell morphology, growth, and autolytic behavior, in a range of conditions showed that 4 PGHs (Acm2, Lys2, LytA, and LytH) play important roles either in the cell cycle or in the autolysis process of L. plantarum. Notably, we demonstrated that the putative $N$-acetylglucosaminidase Acm 2 is the major autolysin of $L$. plantarum and that the putative $\gamma$-D-glutaminyl-meso-diaminopimelate muropeptidase LytA is a major morphogenic determinant in L. plantarum, thereby establishing a novel role for D,L-endopeptidases of the NLPC/P60 family.

\section{Methods}

\section{Bacterial strains, plasmids, and growth conditions}

The bacterial strains and plasmids used in the present study are listed in Table 1. Plasmids were constructed in Escherichia coli DH5 $\alpha$ or in Lactococcus lactis subsp. cremoris NZ3900. E. coli was grown in LB medium with aeration at $37^{\circ} \mathrm{C}$. L. plantarum and L. lactis were grown at $28^{\circ} \mathrm{C}$ in MRS broth (Difco Laboratories Inc., Detroit, MI) and M17 broth (BD Biosciences) supplemented with 0.5\% glucose (M17-glucose), respectively. When appropriate, antibiotics were added to the media at the following concentrations: erythromycin at $250 \mu \mathrm{g} / \mathrm{ml}$ for E. coli and at 5 $\mu \mathrm{g} / \mathrm{ml}$ for L. plantarum and Lactococcus lactis, and chloramphenicol at $10 \mu \mathrm{g} / \mathrm{ml}$ for E. coli, L. plantarum and Lactococcus lactis. Plating media were prepared by adding $2 \%$ (w/v) agar to the medium. Chemically defined medium (CDM) and stress chemically defined medium (SCDM) used in this study were prepared as previously described [23]. SCDM deviates from CDM by a two-fold higher 
Table 1 Bacterial strains and plasmids used in this study

\begin{tabular}{|c|c|c|}
\hline $\begin{array}{l}\text { Strain or } \\
\text { plasmid }\end{array}$ & Characteristic(s) & $\begin{array}{l}\text { Source or } \\
\text { reference }\end{array}$ \\
\hline \multicolumn{3}{|c|}{ Lactobacillus plantarum } \\
\hline NZ7100 & WCFS1 Ip_0076::nisRK & [46] \\
\hline TR0010 & NZ7100 Ip_2645 (acm2)::Iox72 & This work \\
\hline TR0011 & NZ7100 Ip_3093 (lys2)::Iox72 & This work \\
\hline TR0012 & NZ7100 Ip_1138 (acm1)::Iox72 & This work \\
\hline TR0013 & NZ7100 Ip_1158 (lys1)::10x72 & This work \\
\hline TR0014 & NZ7100 Ip_1982 (lytH)::Iox72 & This work \\
\hline TR006 & NZ7100 Ip_3421 (lytA)::Iox66-P32-cat-lox71 & This work \\
\hline TR0015 & NZ7100 Ip_2162 (lytB)::Iox72 & This work \\
\hline TR0016 & NZ7100 Ip_1242 (lytD):::/ox72 & This work \\
\hline TR0017 & NZ7100 Ip_0302 (m/tA)::I0x72 & This work \\
\hline TR0018 & TR0011 Ip_2645 (acm2)::Iox72 & This work \\
\hline \multicolumn{3}{|c|}{ Escherichia coli } \\
\hline $\mathrm{DH} 5 \mathrm{a}$ & 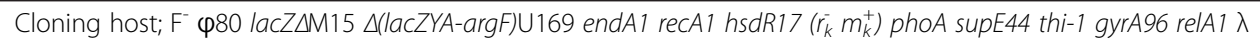 & [47] \\
\hline \multicolumn{3}{|c|}{ Lactococcus lactis } \\
\hline NZ3900 & MG1363 derivative, pepN::nisRK & [30] \\
\hline \multicolumn{3}{|l|}{ Plasmids } \\
\hline pNZ5319 & $\begin{array}{l}\mathrm{Cm}^{r} \mathrm{Em}^{\mathrm{r}} \text {; pACYC184 derivative containing the cat gene under the control of the P32 constitutive promoter of } \\
\text { Lactococcus lactis (Iox66-P32-cat-lox71 cassette) }\end{array}$ & [29] \\
\hline pNZ5348 & $\mathrm{Em}^{\mathrm{r}}$; Cre expression vector & [29] \\
\hline pNZ8048 & $\mathrm{Cm}^{r}$; shuttle vector containing $\mathrm{P}_{\text {nisA }}$ promoter and start codon in Ncol site & [48] \\
\hline pGITR001 & $\mathrm{Cm}^{r} \mathrm{Em}^{\mathrm{r}}$; pNZ5319 containing both upstream and downstream homology fragments from Ip_2645 (acm2) & This work \\
\hline pGITR002 & $\mathrm{Cm}^{\mathrm{r}}$ Emr; pNZ5319 containing both upstream and downstream homology fragments from Ip_3093 (lys2) & This work \\
\hline pGITR003 & $\mathrm{Cm}^{r}$ Emr; pNZ5319 containing both upstream and downstream homology fragments from Ip_1138 (acm1) & This work \\
\hline pGITR004 & $\mathrm{Cm}^{r} \mathrm{Em}^{\mathrm{r}}$; pNZ5319 containing both upstream and downstream homology fragments from Ip_1158 (lys1) & This work \\
\hline pGITR005 & $\mathrm{Cm}^{r} \mathrm{Em}^{\mathrm{r}} ; \mathrm{pNZ5319}$ containing both upstream and downstream homology fragments from Ip_1982 (lytH) & This work \\
\hline$\overline{\text { pGITR006 }}$ & $\mathrm{Cm}^{\mathrm{r}} \mathrm{Em}^{\mathrm{r}}$; pNZ5319 containing both upstream and downstream homology fragments from Ip_3421 (lytA) & This work \\
\hline pGITR007 & $\mathrm{Cm}^{r}$ Emr; pNZ5319 containing both upstream and downstream homology fragments from Ip_2162 (lytB) & This work \\
\hline pGITR008 & $\mathrm{Cm}^{r}$ Emr; pNZ5319 containing both upstream and downstream homology fragments from Ip_1242 (lytD) & This work \\
\hline pGITR009 & $\mathrm{Cm}^{r} \mathrm{Em}$; pNZ5319 containing both upstream and downstream homology fragments from 1 p_0302 (m/tA) & This work \\
\hline pGITR0010 & $\mathrm{Cm}^{\mathrm{r}}$; pNZ8048 derivative containing acm2 (Ip_2645) gene in transcriptional fusion & This work \\
\hline$\overline{\text { pGITR0011 }}$ & $\mathrm{Cm}^{\mathrm{r}}$; pNZ8048 derivative containing lys2 (Ip_3093) gene in transcriptional fusion & This work \\
\hline
\end{tabular}

$\mathrm{Cm}^{r}$ and $\mathrm{Em}^{r}$ indicate resistance to chloramphenicol and erythromycin, respectively.

concentration of amino acids and addition of $300 \mathrm{mM}$ $\mathrm{NaCl}$. L. plantarum was grown in SCDM at $37^{\circ} \mathrm{C}$. Nisin A (Sigma-Aldrich) was routinely used at a concentration of $20 \mathrm{ng} / \mathrm{ml}$ for the induction of genes that were cloned under the control of the nisA promoter [24].

\section{DNA techniques and electrotransformation}

General molecular biology techniques were performed according to the instructions given by Sambrook et al. [25]. Electrotransformation of E. coli was performed as described by Dower et al. [26]. Electrocompetent L. plantarum and $L$. lactis cells were prepared as previously described [27]. L. plantarum chromosomal DNA was isolated as reported before [28]. PCR were performed with
Phusion high-fidelity DNA polymerase (Finnzymes, Espoo, Finland) in a GeneAmp PCR system 2400 (Applied Biosystems, Foster City, CA). The primers used in this study were purchased from Eurogentec (Seraing, Belgium) and are listed in (Additional file 1: Table S1).

\section{Construction of deletion mutants}

Construction of the deletion mutants of the L. plantarum PGH-encoding genes was performed as previously described $[2,29]$. Briefly, a double cross-over gene replacement strategy was used to replace the target gene (s) by a chloramphenicol resistance cassette (lox66-P32cat-lox71). Subsequently, the lox66-P32-cat-lox71 cassette was excised by temporal expression of the Cre 
recombinase using an unstable cre expression plasmid [29]. This strategy was applied for the construction of strains TR0010 (Acm2-), TR0011 (Lys2 $\left.{ }^{-}\right), \quad$ TR0012

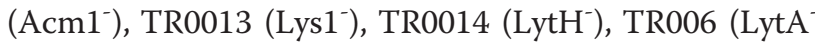

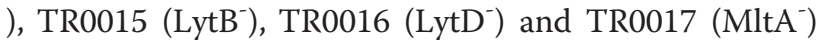
(Table 1). In order to obtain the double mutant strain TR0018 (Acm2- Lys2), strain TR0011 (Lys2) was used for a next round of mutagenesis targeting for the deletion of acm 2 following the same procedures as described above. Primers used to construct the deletion vectors and to validate the deletions events are listed in (Additional file 1: Table S1).

\section{Construction of the complementation vectors}

The acm 2 and lys 2 ORFs were amplified by PCR using genomic DNA of L. plantarum NZ7100 and the primer pairs Acm2_NcoI/Acm2_XbaI or Lys2_NcoI/Lys2_XbaI, respectively (Additional file 1: Table $\mathrm{S} 1$ ). The resulting amplicons were digested with $\mathrm{NcoI}$ and $\mathrm{XbaI}$ and cloned into similarly digested pNZ8048, yielding the expression plasmids pGITR0010 and pGITR0011, respectively. These plasmids contain either acm 2 or lys 2 under the control of $\mathrm{P}_{\text {nis }}$ that allows their induction in the presence of nisin [30]. The integrity of the two plasmids was verified by DNA sequencing. These two expression vectors were electrotransformed into L. plantarum TR0010 for complementation studies. Primers used to construct the complementation vectors are listed in (Additional file 1: Table S1).

\section{Purification and structural analysis of peptidoglycan}

PG from L. plantarum strains was prepared as previously described [2,31]. PG was digested with mutanolysin and the resulting muropeptides were analyzed by reverse phase-high-pressure liquid chromatography (RPHPLC) and MALDI-TOF (Matrix-Assisted Laser Desorption/Ionization - Time Of Flight) mass spectrometry as previously reported [32].

\section{Triton X-100-induced autolysis assays in buffer solution}

L. plantarum strains were grown to mid-exponential phase $\left(\mathrm{OD}_{600}=0.8\right)$. Cells were harvested by centrifugation at $5000 \times g$ for $10 \mathrm{~min}$ at $4^{\circ} \mathrm{C}$, washed once with 50 $\mathrm{mM}$ potassium phosphate buffer $\mathrm{pH} 7.0$, and resuspended at an $\mathrm{OD}_{600}$ of 1.0 in $50 \mathrm{mM}$ potassium phosphate buffer pH 7.0 supplemented with $0.05 \%$ Triton $\mathrm{X}-100[2,33]$. Cell suspensions were then transferred into 96-well sterile microplates with a transparent bottom (Greiner, Alphen a/d Rjin, the Netherlands) and incubated at $30^{\circ} \mathrm{C}$. Autolysis was monitored by measuring the $\mathrm{OD}_{600}$ of the cell suspensions every 20 minutes with a Varioskan Flash multimode reader (Thermo Scientific). The extent of autolysis was expressed as the relative decrease in $\mathrm{OD}_{600}$ (given in percentages relative to the initial $\mathrm{OD}_{600}$ ).

\section{SDS-PAGE and zymogram}

The cell wall hydrolyzing activity was investigated by zymogram analysis. SDS-PAGE was performed with $8 \%$ $(\mathrm{w} / \mathrm{v})$ polyacrylamide separating gels. Renaturing SDSPAGE was performed as previously described [2,34]. The polyacrylamide gels contained $L$. plantarum NZ7100 autoclaved cells resuspended at $\mathrm{OD}_{600}$ of 0.8 as enzyme substrates. Disrupted cells used as samples were prepared as described before [2]. Disrupted cells were boiled in denaturing sample buffer and centrifuged 1 $\min$ at $20.000 \times g$ prior to loading. After sample migration, gels were washed for $30 \mathrm{~min}$ in deionized $\mathrm{H}_{2} \mathrm{O}$ and incubated overnight at room temperature in $50 \mathrm{mM}$ Tris- $\mathrm{HCl}, \mathrm{pH}$ 6.8, $1 \mathrm{mM}$ DTT, containing $0.1 \%$ (v/v) Triton X-100. Subsequently, the gels were washed in deionized $\mathrm{H}_{2} \mathrm{O}$, followed by staining with $0.1 \%$ Methylene Blue in $0.01 \%(\mathrm{w} / \mathrm{v}) \mathrm{KOH}$, and destained in deionized $\mathrm{H}_{2} \mathrm{O}$.

\section{Fluorescence microscopy and LIVE/DEAD staining}

Microscopy analyses were performed using an Axio observer Z1 inverted microscope (Carl Zeiss). FM4-64 (Molecular Probes, Leiden, The Netherlands) and DAPI (4, 6-diamidino-2-phenylindole) (Sigma, Bornem, Belgium) staining were performed as previously reported [31]. Bacterial membrane integrity was assessed by fluorescence microscopy using a LIVE/DEAD reduced biohazard viability/cytotoxicity kit (Molecular Probes, Eugene, OR, USA) according to the manufacturer's instructions. Analyses of micrographies were performed using the AxioVision 4.8. software (Carl Zeiss).

\section{Transmission and scanning electron microscopy}

L. plantarum cells were grown overnight at $28^{\circ} \mathrm{C}$ in MRS broth. Bacterial pellets were washed once in PBS and fixed overnight in a phosphate buffer $(0.1 \mathrm{M}$ and $\mathrm{pH}$ 7.4) containing $2.5 \%$ glutaraldehyde for transmission electron microscopy or $4 \%$ paraformaldehyde for scanning electron microscopy. After fixation, cells were washed, postfixed with $1 \%$ osmium tetroxide for $1 \mathrm{~h}$, washed again and subjected to serial dehydration with ethanol. Samples for transmission electron microscopy were embedded in resin, thin-sectioned and stained with uranyl acetate and Reynold's lead citrate. Samples for scanning electron microscopy were prepared by criticalpoint drying, mounted on an aluminum stub and covered with a thin layer of gold $(20-30 \mathrm{~nm})$. Finally, the samples were examined using a Transmission Electron Microscope (TEM) (LEO922; Zeiss) at the Institute of Condensed Matter and Nanosciences (Université catholique de Louvain, Belgium) or a Scanning Electron 
Microscope (SEM) (XL-20; Philips, Eindhoven, the Netherlands) at the Unité Interfacultaire de Microscopie Electronique (Facultés Universitaires Notre-Dame de la Paix, Belgium).

\section{Results}

Nine of the twelve predicted peptidoglycan hydrolases could be inactivated in L. plantarum WCFS1

We have previously identified 12 genes in the L. plantarum WCFS1 genome coding for orthologs of wellcharacterized PGHs of Gram-positive bacteria [12,16]. As shown in Figure 1, these putative PGHs can be classified into five families according to the PFAM accession number of their catalytic domains: Acm1 (Lp_1138) and Acm2 (Lp_2645) belong to the family of Mannosyl-glycoprotein endo-beta- $N$-acetylglucosaminidase (PF01832); Lp_1158 and Lp_3093, renamed Lys1 and Lys2, respectively, belong to the muramidase family of Glycosyl hydrolases 25 (PF01183); LytH (Lp_1982) belongs to the $\mathrm{N}$-acetylmuramoyl-L-alanine amidase family (PF01520); Lp_3421, Lp_2162, Lp_2520, and Lp_1242, renamed LytA, LytB, LytC, and LytD, respectively, belong to the $\gamma$-D-Glu-mDAP muropeptidase family containing a NLPC/P60 catalytic domain (PF00877); Lp_0302, Lp_3014, and Lp_3015, renamed MltA, MltB, and $\mathrm{MltC}$, respectively, belong to the lytic transglycosylase family (PF06737). All 12 PGHs possess a putative signal peptide based on SignalP 4.0 predictions (http:// www.cbs.dtu.dk/services/SignalP). Some redundancy can be observed in terms of domain organization within and between the different PGH families. Interestingly, 8 of the 12 PGHs show a modular organization where their catalytic domain is associated with at least one PG binding domain (SH3_3, SH3_5, or LysM) and/or with a

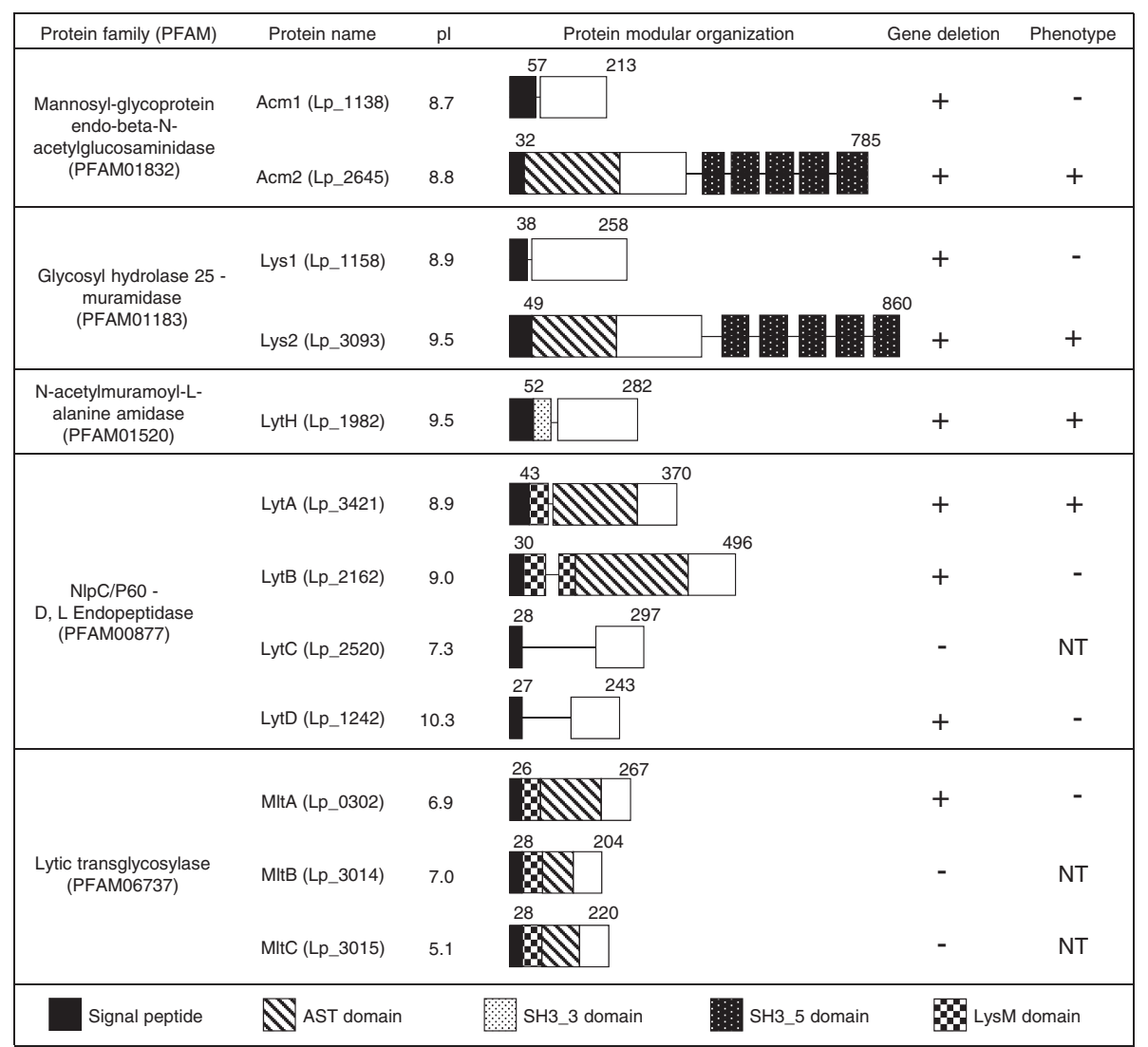

Figure 1 Schematic representation of the modular organization of predicted PGHs identified in L. plantarum WFCS1. Domain annotation is based on conserved domain database (CDD, http://www.ncbi.nlm.nih.gov/Structure/cdd/cdd.shtml) and PFAM database (http://www.sanger.ac. uk/Software/Pfam/). Numbers at the beginning and at the end of each PGH indicate respectively the length (aa) of the signal peptide predicted by the SignalP 4.0 server (http://www.cbs.dtu.dk) and of the full length protein. Isolelectric points (pl) of the predicted mature proteins are calculated by the Compute pl/Mw tool available on ExPASy (http://web.expasy.org/compute_pi/). Cell-wall binding domains SH3_3, SH3_5, and LysM were assigned from PFAM accession numbers, PF08239, PF08460, and PF01476, respectively. The AST domain is a region of unknown function rich in alanine, serine and threonine residues shown to be O-glycosylated in Acm2 (Lp_2645) [19]. Symbols + and - indicate that either the gene deletion or a differential phenotype compared to the wild-type (i.e. cell morphology, growth, or autolysis) were or not obtained or observed, respectively. NT (not tested) indicates that the phenotype could not be tested since the corresponding gene deletion was not obtained. 
domain rich in Ala, Ser and Thr (AST), recently shown to be glycosylated for L. plantarum WCFS1 Acm2 [19].

In order to investigate the functional role of each PGH, we aimed to construct a library of $L$. plantarum PGH mutant strains using the double cross-over gene replacement strategy based on the Cre-loxP system [29]. During the first step of this strategy, we attempted to inactivate the targeted open reading frames through replacement by a chloramphenicol resistance cassette (lox66-P32-cat-lox71). Using this approach, we obtained mutants for 9 of the 12 genes that were initially targeted (Figure 1). Despite several attempts in which over 300 integrants were tested for their genotype, we were not able to obtain double cross over events for $l y t C, m l t B$, and $m l t C$, suggesting that they might be essential for bacterial survival. Subsequently, the lox66-P32-cat-lox71 cassette was successfully excised from 8 of the 9 mutants (all except the $l y t A$ that could no longer be transformed by electroporation) by temporal expression of the Cre recombinase [29].

Since in our tested conditions, four PGH-deficient strains (Acm2 $2^{-}, \mathrm{Lys}^{-}$, LytA ${ }^{-}$, and $\mathrm{LytH}^{-}$) were later shown to display phenotypic differences as compared to the wild type (see below), construction of complementation vectors for each of these PGH was attempted. The cloning of $a c m 2$ and lys 2 genes under the transcriptional control of the nisin-inducible promoter [24,30] was achieved and corresponding complemented strains were constructed. Despite numerous attempts, complementation of $\mathrm{LytA}^{-}$and $\mathrm{LytH}^{-}$mutant strains were not obtained since the cloning of $l y t A$ and $l y t H$ genes in various hosts ( $E$. coli, L. lactis, and L. plantarum) was unsuccessful. We only obtained truncated gene copies of $l y t A$, while for $l y t H$, when full-length gene cloning was successful, all candidates contain point mutations resulting in inactive proteins (data not shown).

\section{Acm2 and LytA are involved in cell separation and cell division}

As a first characterization of the 9 PGH mutant strains, their cell morphology in exponential and stationary growth phases was examined by light microscopy. Cells were grown in MRS medium, chemically defined medium (CDM), and CDM under mild stress conditions (termed SCDM medium here, see Materials and Methods). Cells were grown in CDM since a recent report by Bron et al. [35] showed that seven PGH-encoding genes of $L$. plantarum WCFS1 were specifically up-regulated (acm1, lys2, lytC, lytD, and $m t l B)$ or down-regulated (lyt $H$ and $m l t C$ ) in this growth medium under mild stress conditions such as high salt concentration and elevated growth temperature (FermDB platform, http:// www.cmbi.ru.nl/fermDB and Additional file 1: Table S2). Two $(a c m 2, l y t A)$ out of the nine single mutants displayed a different cell morphology compared to the wild type, which was independent of the growth stage or culture conditions (data not shown and Figure 2). The acm 2 mutant is characterized by the formation of long chains of incompletely separated cells, as was previously reported for a single cross-over mutant [20] (Figure 2G and $2 \mathrm{H}$ ). The complemented mutant carrying the acm 2 gene on a multicopy plasmid showed a complete absence of this cell chaining phenotype (data not shown). Concerning the lyt $A$ mutant, it is characterized by the loss of its rod-shape, the presence of a range of different cell morphotypes, and a tendency to form clumps of aggregated cells (Figure $2 \mathrm{M}$ and $2 \mathrm{~N}$ ). To investigate if $a c m 2$ and $l y t A$ mutant cells displayed additional unusual features such as abnormal separation of nucleoids or multiple septa, DNA and cell membrane were stained with DAPI and FM4-64, respectively. For the acm $2 \mathrm{mu}$ tant, cells displayed well-separated nucleoids and no multiple septa could be observed, thus representing a phenotype very similar to wild-type cells (Figure 2C, 2D, 2I, and 2J). For the lytA mutant, despite its aberrant cell morphology, all cells retained DNA material and individual cells did not show multiple septation events (Figure $2 \mathrm{~N}, 2 \mathrm{O}$ and $2 \mathrm{P}$ ). In order to further investigate the cell structure of the mutant collection in more detail, transmission and scanning electron microscopy (TEM and SEM) were performed on cells grown in MRS conditions. Only the acm 2 and $l y t A$ mutants showed cell structure defects compared to the wild type (data not shown and Figure 2). For these two mutants, differences were observed in the septal area at the separation stage of daughter cells. While newly formed poles of wild-type cells could be qualified as blunt (Figure 2E, Additional file 1: Figure S1A), they appeared to be more pointed in acm 2 mutant cells, probably resulting from a delayed or incomplete cell separation (Figure $2 \mathrm{~K}$ and 2L; Additional file 1: Figure S1A). Concerning lytA mutant cells, septa are frequently misplaced and showed a range of abnormalities with accumulation of cell wall material (Figure 2Q and 2R; Additional file 1: Figure S1B) compared to wild-type cells which contain well-defined septa located at mid-cell (Figure 2F; Additional file 1: Figure S1B). These aberrant septation events explained the range of cell morphotypes and the cell aggregation phenotype of the lytA mutant.

These morphological observations demonstrate that Acm 2 and LytA are key actors of the cell cycle within the PGH complement of L. plantarum, since they play an important role during late cell separation and division process, respectively.

\section{LytA inactivation has a strong negative impact on growth and viability}

To further characterize our collection of PGH mutant strains, their growth characteristics were compared to 

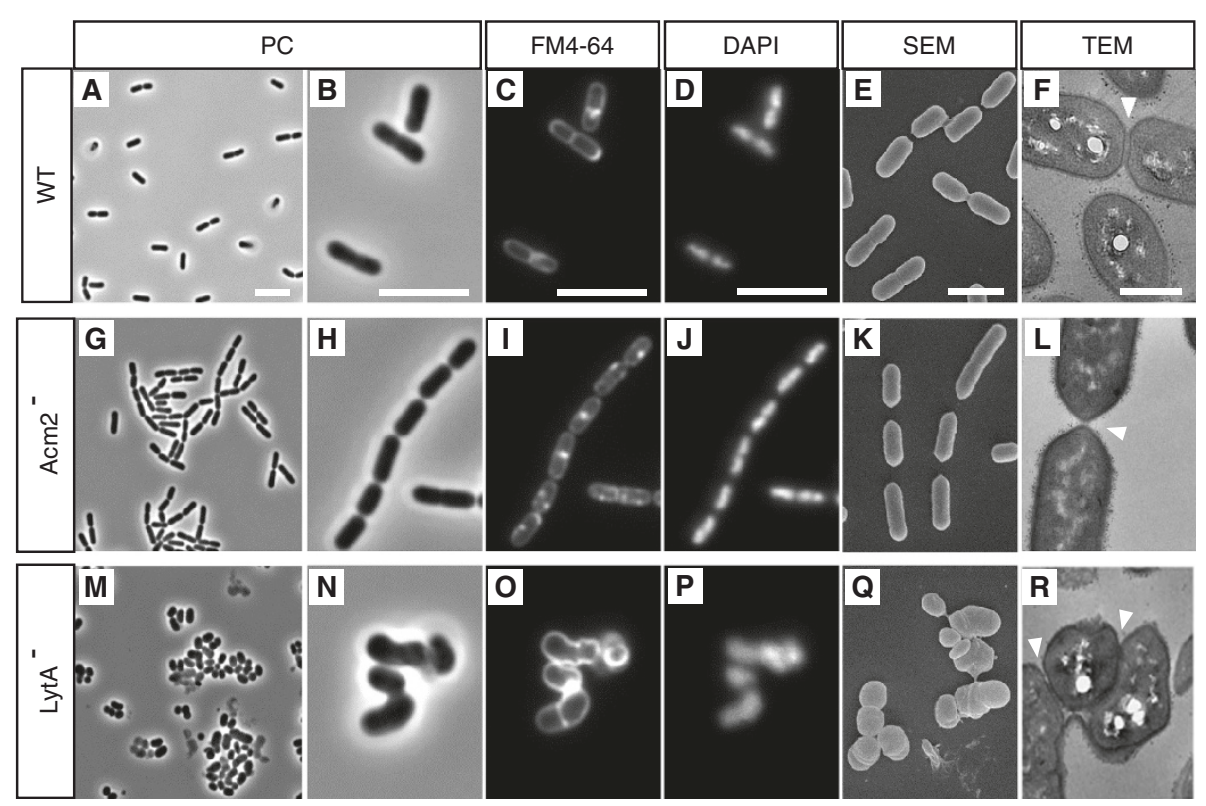

Figure 2 Cell morphology of $L$. plantarum and its mutant derivatives. NZ7100 WT (controls; A, B, C, D, E and F), Acm2 (G, H, I, J, K and L) and $\operatorname{LytA}^{-}(\mathbf{M}, \mathbf{N}, \mathbf{O}, \mathbf{P}, \mathbf{Q}$ and $\mathbf{R})$ mutant strains are presented. Micrographs obtained by phase-contrast (PC) optical microscopy $(\mathbf{A}, \mathbf{B}, \mathbf{G}, \mathbf{H}, \mathbf{M}$ and $\mathbf{N})$, FM4-64 staining $(\mathbf{C}, \mathbf{I}$ and $\mathbf{O})$, DAPI staining ( $\mathbf{D}, \mathbf{J}$ and $\mathbf{P})$, scanning electron microscopy $(\mathrm{SEM})(\mathbf{E}, \mathbf{K}$ and $\mathbf{Q})$ and transmission electron microscopy (TEM) $\left(\mathbf{F}, \mathbf{L}\right.$ and $\mathbf{R}$ ) are shown. Cells for microscopy were grown in MRS medium at $28^{\circ} \mathrm{C}$ and collected in exponential growth phase. The arrows indicate the septum of dividing cells. Bar scales, $5.0 \mu \mathrm{m}$ for PC, FM4-64 and DAPI; $5.0 \mathrm{~nm}$ for SEM and TEM.

the wild type in different conditions (MRS, CDM and $\mathrm{SCDM})$. As shown in Figure 3, the acm2 mutant displayed a similar growth curve compared to the wild type, whereas the $l y t A$ mutant appeared strongly affected in all tested conditions: it displayed a lower growth rate during exponential phase and a reduced $\mathrm{OD}_{600}$ after 15 $\mathrm{h}$ of incubation. No significant differences were observed for the other PGH mutant strains under these three different growth conditions (Additional file 1: Figure S2), except for the $l y t H$ mutant that showed a growth delay only when grown in CDM, albeit to a lesser extent as compared to the lytA mutant (Figure $3 \mathrm{~B}$ ). Taken together, these results show that the acm 2 mutant does not exhibit major growth differences compared to the wild type, whereas the lytA mutant has a strong and constant growth defect that could result from a loss of viability. To test this hypothesis, we performed LIVE/ DEAD viability assays based on cell membrane integrity for both mutant cells collected in exponential and stationary growth phases from MRS cultures. Our results showed that the lytA mutant displays a higher percentage of injured cells compared to the wild type in both exponential and stationary growth phases (19\% vs. $0.3 \%$ and $26.5 \%$ vs. $4 \%$, respectively) whereas the acm $2 \mathrm{mu}$ tant shows a lower percentage of dead cells than the wild type ( 0.25 vs. $0.3 \%$ and $0.75 \%$ vs. $4 \%$, respectively) (Additional file 1: Figure S3).

These results underpinned the prominent role of LytA in L. plantarum cell integrity that is apparent in a range of growth conditions, but also revealed that LytH is important under specific conditions (CDM).

\section{$\mathrm{Acm} 2$ is the major autolysin of $L$. plantarum}

In order to visualize the autolytic content of the different PGH mutant strains, zymography experiments were performed. Total cell extracts from cells grown in MRS, CDM, or SCDM, were separated by SDS-PAGE in the presence of L. plantarum NZ7100 autoclaved cells as substrate. An identical banding pattern of hydrolytic activity was observed in all samples except for the acm 2 mutant where no activity could be detected in any of the growth condition applied (illustrated for cells grown in MRS in Figure 4 and Additional file 1: Figure S4; and data not shown). Since it has been previously shown that the isoelectric point (pI) of PGHs is important for zymographic assay [36], ranging from 5.1 to 10.3 for L. plantarum PGHs (Figure 1), zymographic analysis was performed with cell extracts of the acm 2 mutant at different $\mathrm{pH}$ (between 4.7 and 8.8). However, no additional activity could be detected (data not shown). Dead cells of Micrococcus lysodeikticus, a sensitive substrate classically used for zymographic assays, was also used, resulting in the same outcome (data not shown). To confirm that all the bands of activity positioned between 110 and 60 $\mathrm{kDa}$ could be attributed to Acm 2 and its breakdown products, zymographic assays were preformed with the complemented mutant strain of $L$. plantarum and a $L$. lactis strain overproducing Acm2 from the same 
Figure 3 Growth curves of $L$. plantarum and its mutant derivatives. NZ7100 (WT, lines), acm2 mutant (Acm2', open triangles), lytA mutant (Lyt $\mathrm{A}^{-}$, black triangles) and lytH mutant ( $\mathrm{LytH}^{-}$; open circles) grown in MRS (A), CDM (B) and SCDM (C) are presented. Mean values \pm standard deviations $(n=3)$. $\mathrm{OD}_{600}$ values of the lytA mutant (MRS, CDM, and SCDM) and the lytH mutant (CDM) are all significantly different from the WT between 3 and $15 \mathrm{~h}$. Significance is based on Student's $t$ test with a $P$ value of $<0.001$.

multicopy plasmid (Figure 4). Interestingly, a similar banding pattern was observed for L. plantarum and Lactococcus lactis, showing that all the bands of activity results from Acm 2 and its degradation products. These observations are a first indication that Acm 2 acts as the major PG hydrolytic enzyme of $L$. plantarum.

To better characterize the autolytic behavior of the different PGH mutant strains, Triton X-100-induced autolysis assays were initially performed with cells grown in MRS medium $\left(\mathrm{OD}_{600}\right.$ of 0.8). As shown in Figure 5A, the acm 2 and lytA mutants exhibited a higher autolysis resistance compared to the wild type, whereas no differences in terms of autolysis were observed for the other PGH-deficient strains (illustrated for the lys 2 and $l y t H$ mutants in Figure 5A; and Additional file 1: Figure S5). When autolysis assays were performed with cells grown in $\mathrm{CDM}$ or SCDM, differences in terms of autolysis resistance appeared (Figure $5 \mathrm{~B}$ and $5 \mathrm{C}$ ). Under these growth conditions, acm 2 deficiency still conferred the higher resistance to autolysis, but interestingly, lyt $H$ deficiency (both CDM and SCDM) and lys2 deficiency (only SCDM) also resulted in a reduced autolysis. Considering the facts that lys 2 displays a modular organization very similar to Acm2 and that both enzymes are potential hydrolases of glycan strands (Figure 1), we hypothesized that they could act complementary in autolysis resistance. In order to test this hypothesis, a double acm 2 lys 2 mutant was constructed and evaluated for its autolytic behavior. In the case of SCDM growth conditions, the double mutant displayed a higher autolysis resistance compared to the single acm 2 mutant during an incubation period of 7 to 15 hours (Figure 5C). These results corroborate the transcriptomic data that revealed that lys2 was specifically induced in SCDM compared to $\mathrm{CDM}$, whereas the expression profile of $\mathrm{acm} 2$ remained unchanged (Additional file 1: Table S2). These observations support the hypothesis of a complementary role of these two PGHs. In contrast, in the same stressful growth conditions, the $l y t A$ mutant displayed a decrease of its autolysis resistance compared to MRS conditions and behaved as the wild type (Figure 5A and $5 \mathrm{C}$ ). The absence of impact of LytA inactivation regarding to autolysis in SCDM may be explained by the induction of $l y t C$ and $l y t D$ that could complement lytA inactivation (Additional file 1: Table S2). No differences of autolysis 
resistance were observed for cells grown in CDM or SCDM for the other PGH-deficient strains (Additional file 1: Figure S5).

Taken together, these data show that Acm2 is the dominant autolysin of L. plantarum but also that Lys2, LytH and LytA can contribute to autolysis under specific growth conditions. These results are in agreement with DNA microarray expression profiles that have shown that growth conditions and more particularly mild stress conditions can modulate the expression of PGHencoding genes [35].

\section{Lys2 and Acm2 are redundant peptidoglycan hydrolases involved in cell separation}

To further support the hypothesis of a functional redundancy between lys 2 and Acm2, additional investigations of the phenotypes of the corresponding mutants were performed. Since the acm 2 mutant cells have a phenotype that includes a defect in cell separation, we compared the number of cells per chain exhibited by the acm2, lys 2 single mutants and the double mutant with the wild type strain grown in MRS, CDM, or SCDM (Figure 6A). While the inactivation of Acm2 was mainly responsible for the chaining phenotype in all conditions tested, our data also revealed that the number of cells per chain of the double acm 2 lys 2 mutant was significantly increased compared to the single acm 2 mutant when grown in SCDM. This observation indicates that

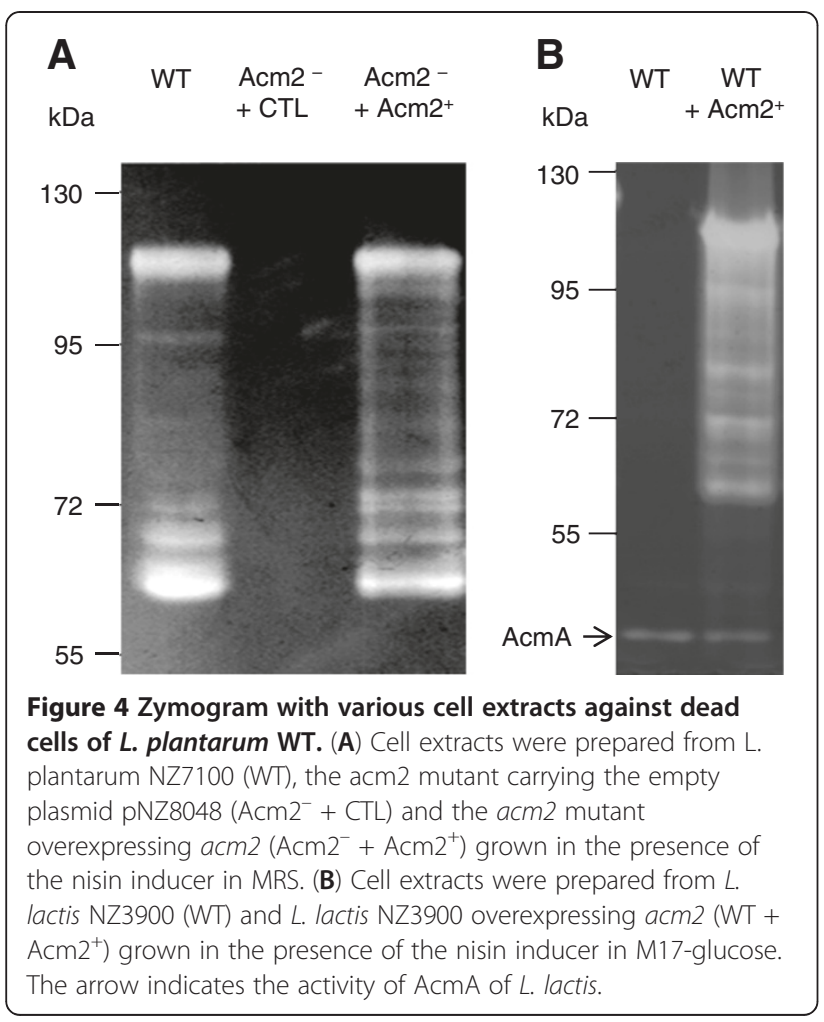

Lys2 contributes to Acm2-driven cell separation of daughter cells only under these growth conditions. To support these data, the acm 2 mutant complemented either by acm 2 or lys 2 were compared. The functionality of Lys2 in the complemented strain was validated by zymogram analysis (Additional file 1: Figure S6). Both Acm 2 and Lys2 were able to fully complement the phenotype of the acm 2 mutant regarding to the cell separation defect (Figure 6B), whereas Lys2 was slightly less efficient than Acm2 to restore Triton X-100 induced autolysis (Figure 6C). These results strongly suggest that Acm 2 and Lys2 could fulfill similar physiological roles despite their different predicted activities.

\section{Analysis of the peptidoglycan composition of Acm 2 and} LytA-deficient strains reveals their hydrolytic activity

From our phenotypical analyses, Acm 2 and LytA were concluded to be the two major PGHs of L. plantarum based on their importance for cell morphology and autolysis. Therefore, we investigate the composition of the PG of their respective mutant strains in order to determine whether they lead to any PG remodeling effect and to obtain a first indication of their enzymatic activity. To this end, we extracted PG from both mutants and digested it with the $\mathrm{N}$-acetylmuramidase mutanolysin. The resulting muropeptides were separated by RP-HPLC and their elution profile was compared to the wild type for which a detailed analysis of the PG composition was recently described by Bernard et al. [2]. Noteworthy, the wild-type muropeptide profile contains a number of peaks that are likely products of PG digestion by endogenous PGHs [2]. In the Acm2 deficient strain, we observed the complete disappearance of a peak corresponding to a MurNAc linked to a tetrapeptide (MTetra) and a strong reduction of a peak identified as a dimer corresponding to a disaccharide-tetrapeptideMurNAc-tripeptide (G-M-Tri-M-Tetra) or MurNActetrapeptide-disaccharide-tripeptide (M-Tri-GM-Tetra) (Figure 7A and see peaks $\mathrm{n}^{\circ} 3$ and 23c in Additional file 1: Table S3). These two muropeptides are deprived of one GlcNAc residue and result from $N$-acetylglucosaminidase activity. In the LytA deficient strain, 8 peaks were either absent or strongly reduced. All these peaks correspond to muropeptides resulting from a cleavage of the peptide stem between D-Glu and mDAP in the wild type by an enzyme with a $\gamma$-D-Glu-mDAP-muropeptidase specificity (Figure 7B and see peaks $n^{\circ} 5,8,15,18,20,21,25$, and 27b in Additional file 1: Table S3).

These results pinpoint that the presence of Acm 2 and LytA have a direct impact on PG structure with a more pronounced effect for LytA, which generated a higher diversity of cleavage products. These data also suggest that Acm 2 cleaves between GlcNAc and MurNAc as expected from its predicted $N$-acetylglucosaminidase 

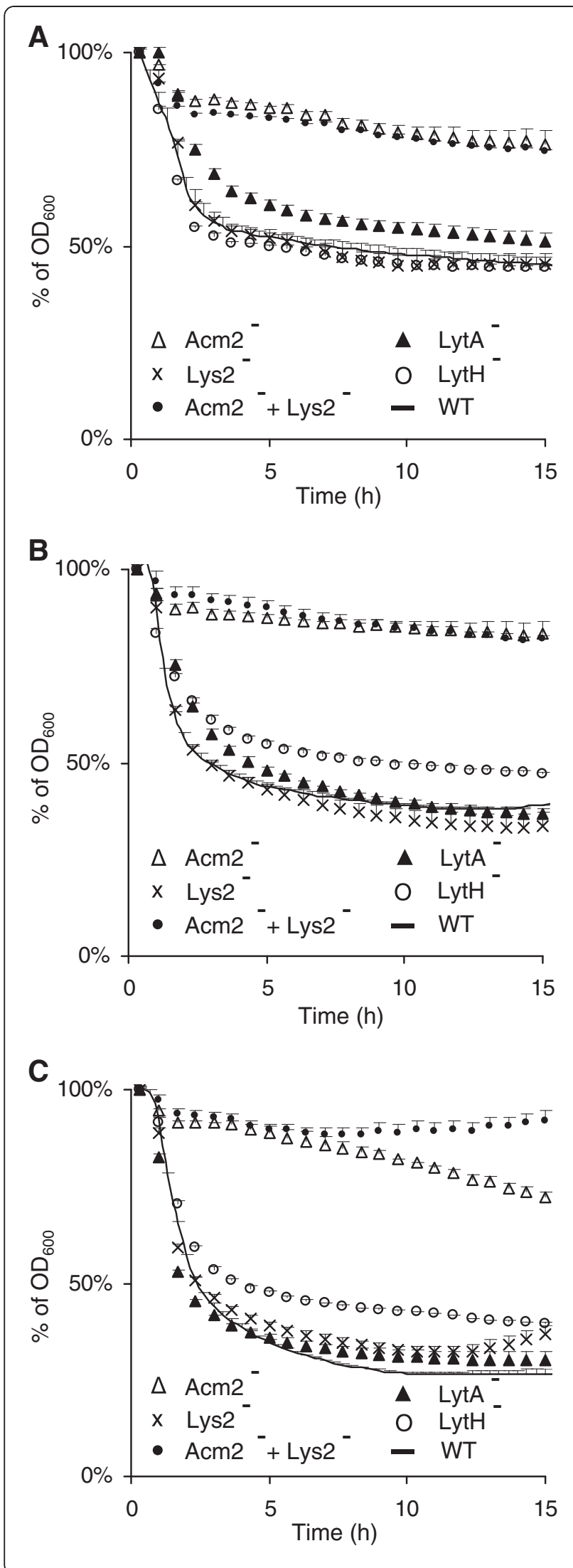

Figure 5 Autolysis of $L$. plantarum and its mutant derivatives in presence of Triton X-100 (0.05\%). Wild type (WT) is represented by a line, acm 2 mutant ( $\mathrm{Acm} 2^{-}$) by open triangles, lys 2 mutant (Lys2 ${ }^{-}$) by crosses, lytA mutant (Lyt $\mathrm{A}^{-}$) by black triangles, lytH mutant $\left(\mathrm{LytH}^{-}\right)$by open circles, and double acm2 lys2 mutant ( $\mathrm{Acm}^{-}+$ Lys2 ${ }^{-}$) by black circles. Cells were grown in MRS (A), CDM (B) and $\operatorname{SCDM}(\mathbf{C})$. Mean values \pm standard deviations $(n=3)$. $\mathrm{OD}_{600}$ values of the acm2 mutant (MRS, CDM, and SCDM), lys2 mutant (SCDM), lytA mutant (MRS), lytH mutant (CDM and SCDM) and double acm2 lys2 mutant (MRS, CDM, and SCDM) are all significantly different from the WT between 4 and $15 \mathrm{~h} . \mathrm{OD}_{600}$ values of the acm 2 lys 2 mutant (SCDM) are all significantly different from the acm2 mutant (SCDM) between 12 and $15 \mathrm{~h}$. Significance is based on Student's $t$ test with a $P$ value of $<0.001$.

activity and its inhibition by $O$-acetylation of GlcNAc [2]. Concerning LytA, our data indicate that it cleaves PG between D-Glu and mDAP, suggesting that LytA displays a $\gamma$-D-Glu-mDAP muropeptidase activity.

\section{Discussion}

The PGH complement of $L$. plantarum WCFS1 contains at least 12 putative PGHs that were all predicted to be secreted. Moreover, most of them are anticipated to display a modular organization (8 PGHs), composed of catalytic domains linked to PG binding domains (SH3 or LysM). Furthermore, we highlighted that more than half of the PGHs of L. plantarum harbored a domain rich in Ala, Ser and Thr (named AST) which was recently shown to be glycosylated [19]. The predominance of this domain among L. plantarum PGHs suggests that it may play a general role in the control of activity and/or stability of these enzymes, as was recently also hypothesized for a glycosylated PGH of L. rhamnosus GG [21]. However, the functional role of the AST domain and of its glycosylated state in L. plantarum regarding to PGH activity/stability but also for spatial PGH localization remains to be investigated. In addition, it was recently shown that a similar domain rich in Ser and Thr (STp) from an extracellular protein of L. plantarum was resistant to intestinal proteolysis and was able to modulate in vitro cytokine production from intestinal dendritic cells [37]. This reveals that such domain could be of importance in the dialogue between intestinal bacteria and the immune system.

In order to elucidate the physiological function(s) of $L$. plantarum PGHs, we underwent a systematic gene deletion strategy to obtain stable, marker-free mutants for each of them. As a result, 9 PGHs were identified as permissive for inactivation, whereas 3 PGHs remained refractory to deletion despite various attempts, suggesting that they may play an essential role in L. plantarum. Among these three PGHs, two belongs to the lytic transglycosylase family whose functional role is poorly understood in Gram-positive bacteria [38]. We next 


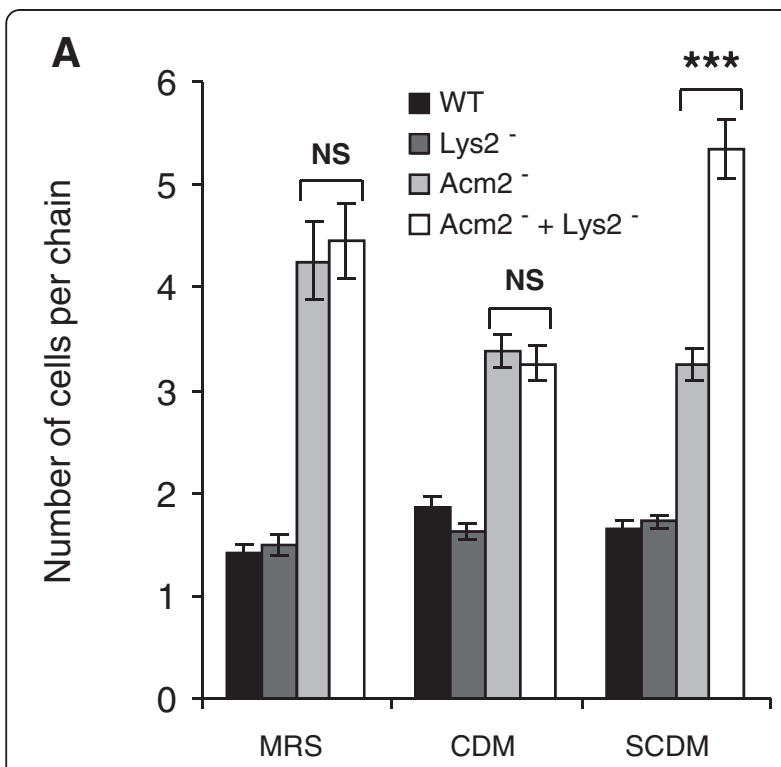

B

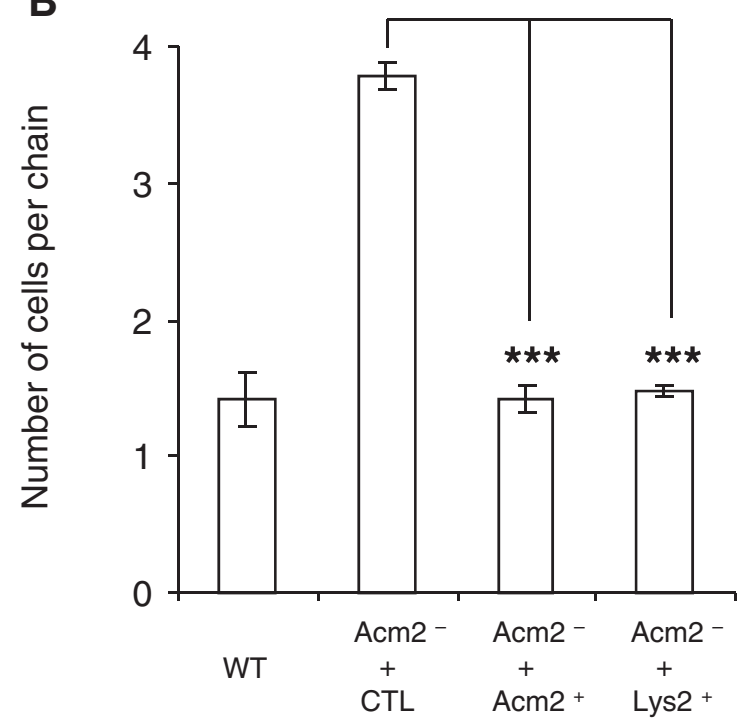

C

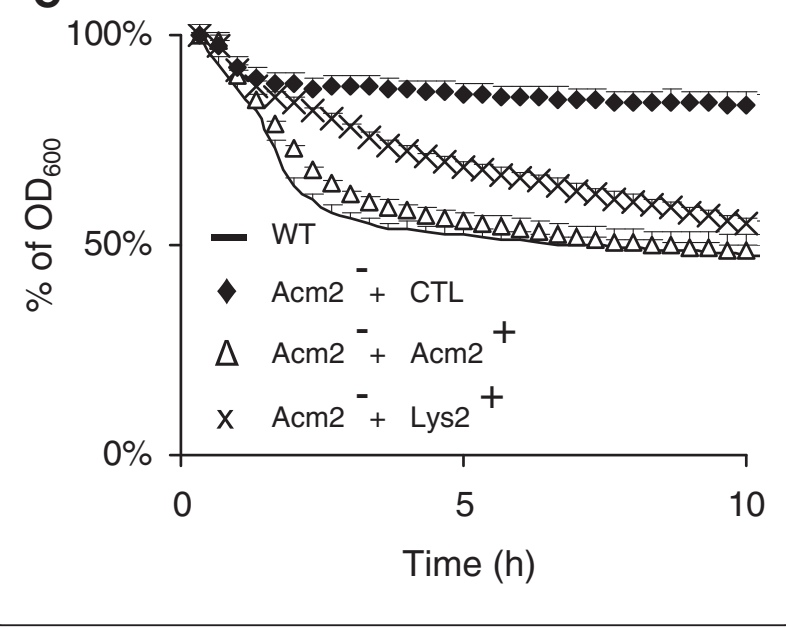

Figure 6 Study of the redundancy between Acm2 and Lys2 for cell chaining and autolysis phenotypes. (A) Number of cells per chain in L. plantarum NZ7100 (WT), acm2 mutant (Acm2-), lys2 mutant (Lys2 $\left.{ }^{-}\right)$, and double acm2 lys2 mutant $\left(\mathrm{Acm}^{-}+\mathrm{Lys}^{-}\right)$in different growth conditions (MRS, CDM and SCDM). (B) Number of cells per chain in L. plantarum NZ7100 (WT), acm2 mutant carrying the empty plasmid pNZ8048 (Acm2 $\left.{ }^{-}+\mathrm{CTL}\right)$, and acm2 mutant overexpressing acm2 $\left(\mathrm{Acm}^{-}+\mathrm{Acm}^{+}\right)$or lys2 $\left(\mathrm{Acm}^{-}+\mathrm{Lys}^{+}\right)$ grown in presence of the nisin inducer in MRS. (C) Autolysis of $L$. plantarum and its mutant derivatives in presence of Triton X-100 (0.05\%). Wild type is represented by a line (WT), acm2 mutant carrying the empty plasmid pNZ8048 (Acm2 $\left.{ }^{-}+\mathrm{CTL}\right)$ by black diamonds, and acm2 mutant overexpressing acm2 ( $\left.\mathrm{Acm} 2^{-}+\mathrm{Acm}^{+}\right)$ and lys2 $\left(\mathrm{Acm}^{-}+\mathrm{Lys}^{+}\right)$by white triangles and crosses, respectively. For panels $A$ and $B$, mean values \pm standard deviations $(n=3)$; significance based on Student's $t$ test; ${ }^{* *}, P$ value of $<0.001$. NS, not significantly different. For panel $C$, mean values of three independent experiments \pm standard deviations (with 3 repetitions for each). $\mathrm{OD}_{600}$ values of the wild type, acm2 mutant overexpressing acm2 $\left(\mathrm{Acm}_{2}+\mathrm{Acm}^{+}\right)$, and acm2 mutant overexpressing lys2 (Acm2 + Lys $^{+}$) are all significantly different from the acm2 mutant carrying the empty plasmid pNZ8048 (Acm2 $\left.{ }^{-}+\mathrm{CTL}\right)$ between 2 and $10 \mathrm{~h}$. Significance is based on Student's $t$ test with a $P$ value of $<0.001$.

investigated the role of the 9 PGHs with respect to cell morphology, growth, and autolysis in various conditions and identified four PGHs, namely Acm2, LytA, Lys2, and LytH, that could be associated to one or more phenotypic defect(s). Among these, Acm 2 and LytA caught our attention since their deficiency resulted in the most severe morphological phenotypes. Acm2, is probably a $N$-acetylglucosaminidase, based on the analysis of the PG structure of its respective mutant strain. Preliminary results of PG degradation experiments with purified Acm2 support the proposed $\mathrm{N}$-acetylglucosaminidase activity (T. Rolain, unpublished data). Phase-contrast, TEM and SEM microscopy show that Acm2 is strictly involved in the last step of cell separation during the septation process. This result is consistent with previous observations of an acm 2 single cross-over mutant and the functional role of AcmA, the major $N$-acetylglucosaminidase of Lactococcus lactis, which shares 34\% of identity with Acm 2 and is also dedicated to cell separation in this species [20,39]. For the second enzyme, renamed LytA, we provided strong evidence for its classification as a $\gamma$-D-Glu-mDAP muropeptidase based on the PG analysis of the mutant strain. The proposed LytA endopeptidase activity is consistent with the fact that all the previous known members of the NlpC/P60 family were characterized as $\gamma$-D-Glu-diaminoacid endopeptidases [11,22,40-42]. Unfortunately, all attempts to clone the corresponding gene or to purify its product in order to definitively prove its enzymatic activity remain so far unsuccessful. The absence of LytA results in a strongly hampered growth, loss of viability, and severe structural defects of the cell wall. However, we cannot exclude that 

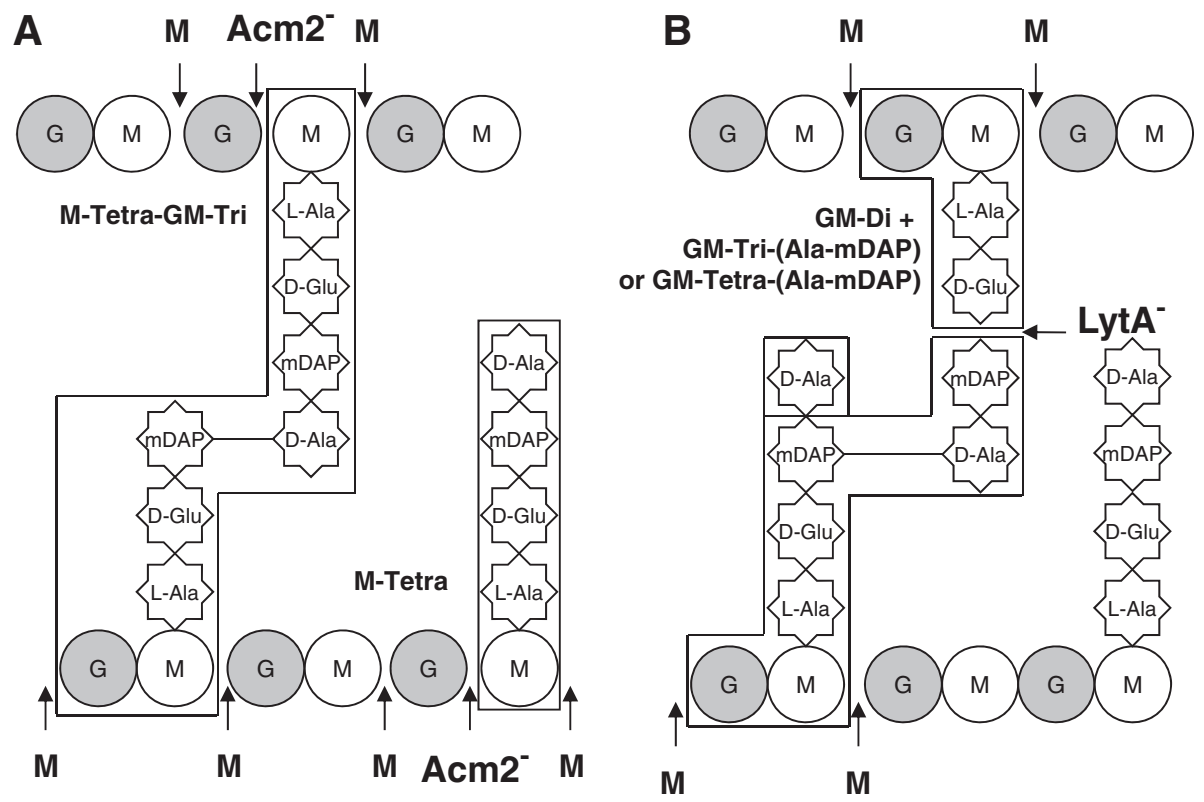

Figure 7 L. plantarum PG structure and modification of muropeptide content resulting from PGH inactivation. Muropeptides that disappear or are strongly reduced resulting from the inactivation of either Acm2 (A) or LytA (B) are boxed. M, MurNAc; G, GlcNAc; Disaccharide, GM. M-Tetra, MurNAc-tetrapeptide; M-Tetra-GM-Tri, MurNAc-tetrapeptide crosslinked to a disaccharide-tripeptide; GM-di, disaccharide-dipeptide; GM-Tri-(Ala-mDAP), disaccharide-tripeptide crosslinked to the dipeptide L-Ala-mDAP from a second peptide stem; GM-Tetra-(Ala-mDAP), disaccharide-tetrapeptide crosslinked to the dipeptide L-Ala-mDAP from a second peptide stem. Cleavage sites of PGHs are indicated by arrows: M (boldface), mutanolysin (N-acetylmuramidase); Acm2- absence of cleavage by a $\mathrm{N}$-acetylglucosaminidase in the PG of the Acm2-deficient strain; and LytA', absence of cleavage by a $\gamma$-D-Glu-mDAP muropeptidase in the PG of the LytA-deficient strain.

polar effects on flanking genes might contribute to the observed phenotype, since we were unable to complement this mutant. Notably, the $l y t A$ gene is predicted to be monocistronic and flanked by genes which are completely unrelated to morphogenesis or cell wall assembly. Interestingly, suppressor mutants were obtained at low frequency without any genetic reorganization of the disrupted locus but displaying a wild-type cell morphology (data not shown), that may suggest that a gene encoding another D,L-endopeptidase of the NlpC/P60 family is activated to counteract the effects of $l y t A$ inactivation. Furthermore, numerous attempts to construct a double LytA/LytB-deficient strain remained so far unsuccessful, suggesting that both enzymes may play redundant but essential roles in L. plantarum. To our knowledge, this is the first time that the inactivation of a PGH containing an NlpC/P60 catalytic domain displays such a severe phenotype while the inactivation of members of this family, including members recently characterized in lactobacilli, leads to a cell-chaining phenotype similar to Acm2 inactivation [6,11,22]. Interestingly, deficiencies in the closely related PG endopeptidases belonging to the cysteine, histidine-dependent amido-hydrolases/peptidase (CHAP) family, such as $\bar{P}$ csB from Streptococcus pneumoniae and LytN from Staphylococcus aureus, also strongly affect growth, cell morphology, and cell wall structure $[43,44]$. Our data suggest that NlpC/P60 endopeptidases can also be implicated in other physiological roles than daughter cell separation and probably play an important role during the assembly of the cell wall by cooperating with the PG synthesis machinery during the division process, as recently shown for the CHAP endopeptidase PcsB from S. pneumoniae [45]. Based on a recent transcriptome profiling study showing that the expression of a large set of PGH-encoding genes from $L$. plantarum are modulated by mild stress conditions, such as high salt concentration and elevated growth temperature [35], the contribution of each PGH to growth and autolysis was examined in different growth media as well as under stress conditions. These experiments revealed that Acm 2 was responsible for the major part of the autolytic activity in all growth conditions tested and should be considered as the major autolysin of $L$. plantarum WCFS1. In addition, these experiments also showed that Lys2, LytH, and LytA contribute to the autolytic process but to a lesser extent than observed for Acm 2 and only under specific growth conditions. We also show that the autolysis of Acm2- and LytAdeficient strains is increased under mild stress conditions showing that stress alters the composition of the PGH complement in L. plantarum, corroborating previously obtained transcriptome data [35]. We hypothesized 
that Acm2 and Lys2, as well as LytA and other members of the NlpC/P60 family, displayed functional redundancy in specific growth conditions. This was further investigated for the potential redundancy between the $\mathrm{N}$-acetylglucosaminidase $\mathrm{Acm} 2$ and the putative $\mathrm{N}$-acetylmuramidase Lys2 where we show that Lys2 could fulfill the functional role of Acm2 regarding to autolysis and cell separation of daughter cells.

\section{Conclusions}

In conclusion, we show that the $\mathrm{N}$-acetylglucosaminidase Acm 2 and the $\gamma$-D-Glu-mDAP muropeptidase LytA are pivotal in the physiology of L. plantarum. Acm2 is the major autolysin under all conditions tested and is functionally involved in the final step of cell separation during division while LytA is playing a major morphogenic role since its absence not only resulted in delayed growth and loss of viability but also led to severe structural defects of the cell wall. For future applications, the identification of Acm2, in association with Lys2 under stress conditions, as key players in autolysis resistance offers the possibility to develop more robust starter strains or probiotics. In addition, the capacity to modulate $L$. plantarum PG composition by PGH inactivation could change its immunomodulatory properties by impacting on the repertoire of released muramyl peptides interacting with receptors of the innate immune system.

\section{Additional file}

Additional file 1: Table S1. Primers used for cloning and validation. Table S2. Transcriptomic data of PGH-encoding genes of $L$. plantarum WCFS1 grown in chemically defined medium (CDM) at $28^{\circ} \mathrm{C}$ (fermentors $\mathrm{F} 12$ and F27, mean value) vs. $\mathrm{CDM}+300 \mathrm{mM} \mathrm{NaCl}$ at $28^{\circ} \mathrm{C}$ (fermentors $\mathrm{F} 6$ and $F 28$, mean value), $C D M$ at $37^{\circ} \mathrm{C}$ (fermentor F18), and CDM + 300mM $\mathrm{NaCl}+$ two-fold higher concentration of amino-acids at $37^{\circ} \mathrm{C}$ (defined here as SCDM conditions) (fermentor F21) (FermDB platform, http://www.cmbiru.nl/fermDB, [1]). Table S3. Differences in muropeptide composition resulting from $\mathrm{N}$-acetylglucosaminidase and $\mathrm{\gamma}$-D-Glu-mDAP muropeptidase activities between L. plantarum NZ7100 (WT) and TR0010 (Acm2-) or TR006 (LytA-). Figure S1. Cell separation defects of Acm2and LytA- mutant strains compared to NZ7100 (WT, control). A. Micrographs obtained by scanning electron microscopy (SEM) showing more pointed poles (white arrows) after cell separation for Acm2- mutant cells compared to WT cells. B. Transmission electron microscopy (TEM) showing altered septum formation (white arrows) for LytA- mutant cells (IV, V, VI, VII, VIII, and IX) compared to WT cells (II, II, and III). Growth conditions as defined in the legend of Figure 2. Figure S2. Growth curves of L. plantarum NZ7100 (WT), acm1 mutant (Acm1-), lys1 mutant (Lys 1-), lys2 mutant (Lys2-), lytB mutant (LytB-), IytD mutant (LytD-), mt/A mutant (MtIA-), in MRS (A), CDM (B) and SCDM (C). Mean values ( $n=3)$.

Figure S3. Effect of $\mathrm{acm} 2$ and lytA mutations on cell integrity. Percentage of dead cells was monitored in MRS medium in the exponential (6 h) and stationary ( $16 \mathrm{~h}$ ) growth phases for L. plantarum NZ7100 (WT), Acm2-, and LytA-. Cell counting was performed by epifluorescence microscopy using propidium iodide (red; labels damaged cells) and SYTO-9 (green; labels all cells). The percentage of damaged cells labeled with propidium iodide was calculated with respect to the total number of cells labeled with SYTO-9. Enumeration was done for a minimum of 300 cells for each strain. Figure S4. Zymogram with cell extracts of L. plantarum NZ7100 (WT), acm2 mutant (Acm2-), lys2 mutant
(Lys2-), acm1 mutant (Acm1-), lys 1 mutant (Lys1-), lytH mutant (LytH-), lytA mutant (LytA-), lytB mutant (LytB-), lytD mutant (LytD-) and mltA mutant (MltA-) against dead cells of WT. Figure S5. Autolysis curves in presence of Triton X-100 (0.05\%) of L. plantarum NZ7100 (WT), acm 1 mutant (Acm 1-), lys1 mutant (Lys1-), lytB mutant (LytB-), lytD mutant (LytD-), mt/A mutant (MtIA-), in MRS (A), CDM (B) and SCDM (C). Mean values $(n=3)$. Figure $\mathbf{S 6}$. Zymogram with cell extracts of $L$. plantarum NZ7100 (WT), acm2 mutant carrying the empty plasmid pNZ8048 (Acm2- + CTL), and acm2 mutant overexpressing lys2 (Acm2- + Lys2+) grown in presence of the nisin inducer in MRS against dead cells of WT.

\section{Abbreviations}

AST: Domain rich in Ala, Ser, and Thr; CDM: Chemically define medium; CHAP: Cysteine, histidine-dependent amido-hydrolases/peptidase; GlcNAc: Nacetylglucosamine; mDAP: meso-diaminopimelic acid; MurNAc: Nacetylmuramic acid; PG: Peptidoglycan; PGH: Peptidoglycan hydrolase; SCDM: stress chemically define medium; SDS-PAGE: SDS polyacrylamide gel electrophoresis; SEM: Scanning electron microscopy; TEM: Transmission electron microscopy; WT: Wild type.

\section{Competing interests}

The authors declare that they have no competing interests.

\section{Authors' contribution}

$\mathrm{PH}$ and TR designed the project; TR, PC, and EB performed the experimental work; TR, EB, PC, PAB, MK, MPCC and PH analysed the data; TR and PH wrote the paper; $P A B, M K, E B$, and MPCC critically reviewed the paper. All authors approved the final manuscript.

\section{Acknowledgements}

Work in the team of PH was supported by the National Foundation for Scientific Research (FNRS), the Université catholique de Louvain (Fonds Spéciaux de Recherche), and the Research Department of the Communauté française de Belgique (Concerted Research Action). Work in the team of MPCC was supported by INRA (Jeune Equipe grant). EB was the recipient of a Marie Curie fellowship for Early Stage Research Training (EST) of the FP6 LabHealth project (MEST-CT-2004-514428). TR held a doctoral fellowship from FRIA. PH is Research Associate of the FNRS. PAB is partially employed within the research programme of the Kluyver Centre for Genomics of Industrial Fermentation which is part of the Netherlands Genomics Initiative/ Netherlands Organization for Scientific Research. We warmly thank Bernard Hallet for fruitful discussions, Wendy Glenisson for critically reading the manuscript, and Xavier Debolle for giving us access to the electron microscopy platform at FUNDP. We thank Pascale Lipnik and Christian Didembourg for helping us with electron microscopy.

\section{Author details}

${ }^{1}$ Biochimie et Génétique Moléculaire Bactérienne, Institut des Sciences de la Vie, Université catholique de Louvain, Place Croix du Sud 5/L7.07.06, Louvain-la-Neuve B-1348, Belgium. ${ }^{2}$ INRA, UMR1319 Micalis, Jouy-en-Josas F-78350, France. ${ }^{3}$ AgroParisTech, UMR Micalis, Jouy-en-Josas F-78350, France. ${ }^{4}$ TI Food \& Nutrition, Nieuwe Kanaal 9A, Wageningen, PA 6709, The Netherlands. ${ }^{5} \mathrm{NIZO}$ food research, Kernhemseweg 2, Ede, ZB 6718, The Netherlands. ${ }^{6}$ Kluyver Centre for Genomics of Industrial Fermentation, Julianalaan 67, Delft, BC 2628, The Netherlands. ${ }^{7}$ Host Microbe Interactomics Group, Wageningen University, De Elst 1, Wageningen, WD 6708, The Netherlands.

Received: 14 June 2012 Accepted: 3 October 2012 Published: 15 October 2012

\section{References}

1. Delcour J, Ferain T, Deghorain M, Palumbo E, Hols P: The biosynthesis and functionality of the cell-wall of lactic acid bacteria. Antonie Van Leeuwenhoek 1999, 76:159-184.

2. Bernard E, Rolain T, Courtin P, Guillot A, Langella P, Hols P, et al: Characterization of $\mathrm{O}$-acetylation of $\mathrm{N}$-acetylglucosamine: a nove structural variation of bacterial peptidoglycan. J Biol Chem 2011, 286:23950-23958. 
3. Vollmer W, Blanot D, de Pedro MA: Peptidoglycan structure and architecture. FEMS Microbiol Rev 2008, 32:149-167.

4. Smith TJ, Blackman SA, Foster SJ: Autolysins of Bacillus subtilis: multiple enzymes with multiple functions. Microbiology 2000, 146(Pt 2):249-262.

5. Vollmer W, Joris B, Charlier P, Foster S: Bacterial peptidoglycan (murein) hydrolases. FEMS Microbiol Rev 2008, 32:259-286.

6. Layec S, Decaris B, Leblond-Bourget N: Diversity of Firmicutes peptidoglycan hydrolases and specificities of those involved in daughter cell separation. Res Microbiol 2008, 159:507-515.

7. Kleerebezem M, Vaughan EE: Probiotic and gut lactobacilli and bifidobacteria: molecular approaches to study diversity and activity. Annu Rev Microbiol 2009, 63:269-290.

8. Remus DM, Kleerebezem M, Bron PA: An intimate tete-a-tete - how probiotic lactobacilli communicate with the host. Eur J Pharmacol 2011, 668(Suppl 1):S33-S42.

9. van Baarlen P, Troost FJ, van Hemert S, van der Meer C, de Vos WM, de Groot PJ, et al: Differential NF-kappaB pathways induction by Lactobacillus plantarum in the duodenum of healthy humans correlating with immune tolerance. Proc Natl Acad Sci U S A 2009, 106:2371-2376.

10. Bron PA, van Baarlen $P$, Kleerebezem M: Emerging molecular insights into the interaction between probiotics and the host intestinal mucosa. Nat Rev Microbiol 2012, 10:66-78.

11. Claes IJ, Schoofs G, Regulski K, Courtin P, Chapot-Chartier MP, Rolain T, et al: Genetic and biochemical characterization of the cell wall hydrolase activity of the major secreted protein of Lactobacillus rhamnosus GG. PLoS One 2012, 7:e31588.

12. Kleerebezem M, Hols P, Bernard E, Rolain T, Zhou M, Siezen RJ, et al: The extracellular biology of the lactobacilli. FEMS Microbiol Rev 2010, 34:199-230.

13. Macho FE, Pot B, Grangette C: Beneficial effect of probiotics in IBD: Are peptidogycan and NOD2 the molecular key effectors? Gut Microbes 2011, 2:280-286.

14. Macho FE, Valenti V, Rockel C, Hermann C, Pot B, Boneca IG, et al: Antiinflammatory capacity of selected lactobacilli in experimental colitis is driven by NOD2-mediated recognition of a specific peptidoglycanderived muropeptide. Gut 2011, 60:1050-1059.

15. Yan F, Polk DB: Characterization of a probiotic-derived soluble protein which reveals a mechanism of preventive and treatment effects of probiotics on intestinal inflammatory diseases. Gut Microbes 2012, 3:25-28.

16. Boekhorst J, Wels M, Kleerebezem M, Siezen RJ: The predicted secretome of Lactobacillus plantarum WCFS1 sheds light on interactions with its environment. Microbiology 2006, 152:3175-3183.

17. Kleerebezem M, Boekhorst J, van Kraneburg R, Molenaar D, Kuipers OP, Leer $R$, et al: Complete genome sequence of Lactobacillus plantarum WCFS1. Proc Natl Acad Sci U S A 2003, 100:1990-1995.

18. Siezen RJ, Francke C, Renckens B, Boekhorst J, Wels M, Kleerebezem M, et al: Complete resequencing and reannotation of the Lactobacillus plantarum WCFS1 genome. J Bacteriol 2012, 194:195-196.

19. Fredriksen L, Mathiesen G, Moen A, Bron PA, Kleerebezem M, Eijsink VG, et al: The major autolysin Acm2 from Lactobacillus plantarum undergoes cytoplasmic O-glycosylation. J Bacteriol 2012, 194:325-333.

20. Palumbo E, Deghorain M, Cocconcelli PS, Kleerebezem M, Geyer A, Hartung T, et al: D-alanyl ester depletion of teichoic acids in Lactobacillus plantarum results in a major modification of lipoteichoic acid composition and cell wall perforations at the septum mediated by the Acm2 autolysin. J Bacteriol 2006, 188:3709-3715

21. Lebeer S, Claes IJ, Balog Cl, Schoofs G, Verhoeven TL, Nys K, et al: The major secreted protein Msp1/p75 is O-glycosylated in Lactobacillus rhamnosus GG. Microb Cell Fact 2012, 11:15.

22. Regulski K, Courtin P, Meyrand M, Claes IJ, Lebeer S, Vanderleyden J, et al: Analysis of the peptidoglycan hydrolase complement of Lactobacillus casei and characterization of the major gamma-D-Glutamyl-L-Lysylendopeptidase. PLoS One 2012, 7:e32301.

23. Teusink B, Wiersma A, Molenaar D, Francke C, de Vos WM, Siezen RJ, et al: Analysis of growth of Lactobacillus plantarum WCFS1 on a complex medium using a genome-scale metabolic model. J Biol Chem 2006, 281:40041-40048

24. Pavan S, Hols P, Delcour J, Geoffroy MC, Grangette C, Kleerebezem M, et al: Adaptation of the nisin-controlled expression system in Lactobacillus plantarum: a tool to study in vivo biological effects. Appl Environ Microbiol 2000, 66:4427-4432.
25. Sambrook J, Fritsch E, Maniatis T: Molecular cloning: a laboratory manual. 2nd edition. New York, NY, USA: Cold Spring Harbour Laboratory Press; 1989.

26. Dower WJ, Miller JF, Ragsdale CW: High efficiency transformation of E. coli by high voltage electroporation. Nucleic Acids Res 1988, 16:6127-6145.

27. Holo H, Nes IF: High-frequency transformation, by electroporation, of Lactococcus lactis subsp. cremoris grown with glycine in osmotically stabilized media. Appl Environ Microbiol 1989, 55:3119-3123.

28. Ferain T, Hobbs JN Jr, Richardson J, Bernard N, Garmyn D, Hols P, et al: Knockout of the two Idh genes has a major impact on peptidoglycan precursor synthesis in Lactobacillus plantarum. J Bacteriol 1996, 178:5431-5437.

29. Lambert JM, Bongers RS, Kleerebezem M: Cre-lox-based system for multiple gene deletions and selectable-marker removal in Lactobacillus plantarum. Appl Environ Microbiol 2007, 73:1126-1135.

30. de Ruyter PG, Kuipers OP, de Vos WM: Controlled gene expression systems for Lactococcus lactis with the food-grade inducer nisin. Appl Environ Microbiol 1996, 62:3662-3667.

31. Bernard E, Rolain T, Courtin P, Hols P, Chapot-Chartier MP: Identification of the amidotransferase AsnB1 as being responsible for mesodiaminopimelic acid amidation in Lactobacillus plantarum peptidoglycan. J Bacteriol 2011, 193:6323-6330

32. Courtin P, Miranda G, Guillot A, Wessner F, Mezange C, Domakova E, et al: Peptidoglycan structure analysis of Lactococcus lactis reveals the presence of an L,D-carboxypeptidase involved in peptidoglycan maturation. J Bacterio/ 2006, 188:5293-5298.

33. Cornett JB, Shockman GD: Cellular lysis of Streptococcus faecalis induced with triton X-100. J Bacterio/ 1978, 135:153-160.

34. Huard C, Miranda G, Wessner F, Bolotin A, Hansen J, Foster SJ, et al: Characterization of $\mathrm{AcmB}$, an $\mathrm{N}$-acetylglucosaminidase autolysin from Lactococcus lactis. Microbiology 2003, 149:695-705.

35. Bron PA, Wels M, Bongers RS, van Bokhorst V, de Veen H, Wiersma A, Overmars $L$, et al: Transcriptomes reveal genetic signatures underlying physiological variations imposed by different fermentation conditions in Lactobacillus plantarum. PLoS One 2012, 7:e38720.

36. Huard C, Miranda G, Redko Y, Wessner F, Foster SJ, Chapot-Chartier MP: Analysis of the peptidoglycan hydrolase complement of Lactococcus lactis: identification of a third N-acetylglucosaminidase, AcmC. Appl Environ Microbiol 2004, 70:3493-3499.

37. Bernardo D, Sanchez B, Al-Hassi HO, Mann ER, Urdaci MC, Knight SC, et al: Microbiota/Host crosstalk biomarkers: regulatory response of human intestinal dendritic cells exposed to lactobacillus extracellular encrypted Peptide. PLoS One 2012, 7:e36262.

38. Stapleton MR, Horsburgh MJ, Hayhurst EJ, Wright L, Jonsson IM, Tarkowski A et al: Characterization of IsaA and SceD, two putative lytic transglycosylases of Staphylococcus aureus. J Bacteriol 2007, 189:7316-7325.

39. Steen A, Buist G, Horsburgh GJ, Venema G, Kuipers OP, Foster SJ, et al: AcmA of Lactococcus lactis is an N-acetylglucosaminidase with an optimal number of LysM domains for proper functioning. FEBS J 2005 272:2854-2868.

40. Redko Y, Courtin P, Mezange C, Huard C, Chapot-Chartier MP: Lactococcus lactis gene yjgB encodes a gamma-D-glutaminyl-L-lysylendopeptidase which hydrolyzes peptidoglycan. Appl Environ Microbiol 2007, 73:5825-5831.

41. Xu Q, Abdubek P, Astakhova T, Axelrod HL, Bakolitsa C, Cai X, et al: Structure of the gamma-D-glutamyl-L-diamino acid endopeptidase YkfC from Bacillus cereus in complex with L-Ala-gamma-D-Glu: insights into substrate recognition by NIpC/P60 cysteine peptidases. Acta Crystallogr Sect F Struct Biol Cryst Commun 2010, 66:1354-1364.

42. Yamaguchi $H$, Furuhata K, Fukushima $T$, Yamamoto $H$, Sekiguchi J: Characterization of a new Bacillus subtilis peptidoglycan hydrolase gene, $y v c E$ (named $c w / O$ ), and the enzymatic properties of its encoded protein. J Biosci Bioeng 2004, 98:174-181.

43. Frankel MB, Hendrickx AP, Missiakas DM, Schneewind O: LytN, a murein hydrolase in the cross-wall compartment of Staphylococcus aureus, is involved in proper bacterial growth and envelope assembly. J Biol Chem 2011, 286:32593-32605.

44. Ng WL, Kazmierczak KM, Winkler ME: Defective cell wall synthesis in Streptococcus pneumoniae R6 depleted for the essential PcsB putative murein hydrolase or the VicR (YycF) response regulator. Mol Microbiol 2004, 53:1161-1175. 
45. Sham LT, Barendt SM, Kopecky KE, Winkler ME: Essential PcsB putative peptidoglycan hydrolase interacts with the essential FtsXSpn cell division protein in Streptococcus pneumoniae D39. Proc Natl Acad Sci U S A 2011, 108:E1061-E1069.

46. Serrano LM, Molenaar D, Wels M, Teusink B, Bron PA, de Vos WM, et al: Thioredoxin reductase is a key factor in the oxidative stress response of Lactobacillus plantarum WCFS1. Microb Cell Fact 2007, 6:29.

47. Yanisch-Perron C, Vieira J, Messing J: Improved M13 phage cloning vectors and host strains: nucleotide sequences of the M13mp18 and pUC19 vectors. Gene 1985, 33:103-119.

48. Kuipers OP, de Ruyter PG, Kleerebezem M, de Vos WM: Controlled overproduction of proteins by lactic acid bacteria. Trends Biotechnol 1997, 15:135-140.

doi:10.1186/1475-2859-11-137

Cite this article as: Rolain et al:: Identification of key peptidoglycan hydrolases for morphogenesis, autolysis, and peptidoglycan composition of Lactobacillus plantarum WCFS1. Microbial Cell Factories 2012 11:137

\section{Submit your next manuscript to BioMed Central and take full advantage of:}

- Convenient online submission

- Thorough peer review

- No space constraints or color figure charges

- Immediate publication on acceptance

- Inclusion in PubMed, CAS, Scopus and Google Scholar

- Research which is freely available for redistribution 